
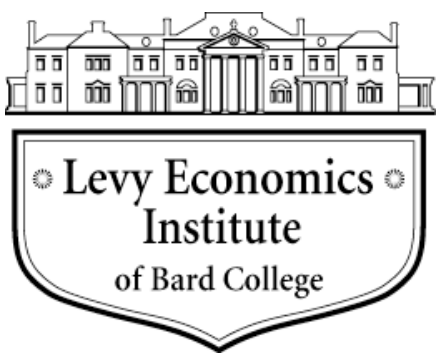

Working Paper No. 859

\title{
The 2030 Sustainable Development Goals and Measuring Gender Inequality: A Technical Articulation for Asia-Pacific
}

\author{
by \\ Bhavya Aggarwal \\ Birla Institute of Technology and Science \\ Lekha S. Chakraborty* \\ Levy Economics Institute of Bard College
}

February 2016

\begin{abstract}
* The authors are, respectively, postgraduate scholar, Birla Institute of Technology and Science (BITS Pilani), Goa; and research associate, Levy Economics Institute of Bard College, and associate professor, National Institute of Public Finance and Policy, New Delhi. This is the revised version of the paper presented by invitation at the UNDP session of the EY International Congress on Economics II, "Growth, Inequality and Poverty," Ankara, Turkey, November 2015. The earlier version of this paper was also presented at the 52nd Annual Conference of the Indian Econometric Society, January 2016. Special thanks are due to the anonymous referees. The usual disclaimer applies.
\end{abstract}

The Levy Economics Institute Working Paper Collection presents research in progress by Levy Institute scholars and conference participants. The purpose of the series is to disseminate ideas to and elicit comments from academics and professionals.

Levy Economics Institute of Bard College, founded in 1986, is a nonprofit, nonpartisan, independently funded research organization devoted to public service. Through scholarship and economic research it generates viable, effective public policy responses to important economic problems that profoundly affect the quality of life in the United States and abroad.

\author{
Levy Economics Institute \\ P.O. Box 5000 \\ Annandale-on-Hudson, NY 12504-5000 \\ http://www.levyinstitute.org
}

Copyright (C) Levy Economics Institute 2016 All rights reserved

ISSN 1547-366X 


\section{ABSTRACT}

Against the backdrop of the 2030 UN Agenda for Sustainable Development, this paper analyzes the measurement issues in gender-based indices constructed by the United Nations Development Programme (UNDP) and suggests alternatives for choice of variables, functional form, and weights. While the UNDP Gender Inequality Index (GII) conceptually reflects the loss in achievement due to inequality between men and women in three dimensions - health, empowerment, and labor force participation — we argue that the assumptions and the choice of variables to capture these dimensions remain inadequate and erroneous, resulting in only the partial capture of gender inequalities. Since the dimensions used for the GII are different from those in the UNDP's Human Development Index (HDI), we cannot say that a higher value in the GII represents a loss in the HDI due to gender inequalities. The technical obscurity remains how to interpret GII by combining women-specific indicators with indicators that are disaggregated for both men and women. The GII is a partial construct, as it does not capture many significant dimensions of gender inequality. Though this requires a data revolution, we tried to reconstruct the GII in the context of Asia-Pacific using three scenarios: (1) improving the set of variables incorporating unpaid care work, pay gaps, intrahousehold decision making, exposure to knowledge networks, and feminization of governance at local levels; (2) constructing a decomposed index to specify the direction of gender gaps; and (3) compiling an alternative index using Principal Components Index for assigning weights. The choice of countries under the three scenarios is constrained by data paucity. The results reveal that the UNDP GII overestimates the gap between the two genders, and that using women-specific indicators leads to a fallacious estimation of gender inequality. The estimates are illustrative. The implication of the results broadly suggests a return to the UNDP Gender Development Index for capturing gender development, with an improvised set of choices and variables.

Keywords: Gender Inequality; Unpaid Work; Human Development; Composite Indicator

JEL Classifications: D63, J16, J31, O15 
The UN document, "Transforming Our World: the 2030 Agenda for Sustainable

Development," agreed to by member states, sets an aspiring vision for gender equality post-2015, determined to "work for a significant increase in investments to close the gender gaps and strengthen support for institutions in relation to gender equality and the empowerment of women at the global, regional and national levels. ..." (para 20). However, globally a data revolution is required to capture the inequalities in gender-sensitive human development, and, in turn, to construct appropriate measurement indices. This challenge is indeed substantial and methodological.

In measuring gender-sensitive human development, the economic growth measures used in early empirical literature had constraints in capturing the wider aspects of well-being and the contingent process of development. Noorbakhsh (1998) noted that the criticisms against using economic growth as the proxy for assessing human development can be traced back to the UN Report of 1954. Since then, the array of literature in favor of using social indicators to measure human development has resulted in the collation of data on a spectrum of socioeconomic indicators across countries, which has inevitably resulted in attempts to construct composite indices of human development and gender inequality (Hicks and Streeten 1979; Morris 1967; Adelman and Morris 1967; UNRISD 1972; UNDP 1995).

Lately, there are many econometric models that analyze the relationship between gender inequality and economic growth, but the statistics and indices about gender inequalities are not adequate for assessing such empirical links with economic growth (Ferrant 2009; Anand and Sen 1995; Dijkstra 2002, 2006). Beyond measuring aggregate affluence, the United Nations Development Program (UNDP) was the pioneer in constructing gender-related indices. The 1995 Human Development Report (HDR) introduced two gender-based indices - the Gender-related Development Index (GDI) and Gender Empowerment Measure (GEM). These were the first composite indices designed to reflect gender disparities in capability deprivation at a global level and were widely used by many researchers across the globe for studying gender disparities between women and men.

\footnotetext{
${ }^{1}$ Available at: https://sustainabledevelopment.un.org/post2015/transformingourworld
} 
Owing to the conceptual and methodological problems identified by researchers in the calculation of these indices, the 2010 HDR introduced a new measure of gender inequality, the Gender Inequality Index (GII). This index was designed to capture women's disadvantage in three dimensions - reproductive health, empowerment, and economic activity. It reflects the loss in achievement due to inequality between men and women. An index of 0 implies that both the genders fare equally in all three select dimensions, whereas an index of 1 implies complete inequality. This paper examines the shortcomings of the existing GII and suggests an alternative choice of variables, functional forms, and methodology to construct a gender inequality index in the context of Asia-Pacific. The choice of countries is constrained by data paucity.

The paper is organized into seven sections. Section I deals with the theoretical and methodological issues in measuring gender inequality. Section II critically analyses GII; while section III provides a critical take on the variables used by UNDP and suggest a new set of variables. Section IV deals with the GII construction using an alternative set of variables with the same functional form. Section V suggests the decomposed indices using a new set of variables. Section VI presents the GII estimates for Asia-Pacific calibrated from the Principal Component Analysis and section VII concludes.

\section{THEORETICAL AND METHODOLOGICAL ISSUES IN MEASURING GENDER INEQUALITY}

The process of enlarging people's choices and raising the level of well-being is defined as human development. Conceptually, these choices can be infinite. These choices can vary intertemporally

and spatially. From the infinite set of choices, the UNDP had selected three dimensions as the most critical and socially valuable: the ability to lead a long and healthy life; the choice to acquire knowledge and be educated; and access to resources needed for a decent level of living (UNDP Human Development Reports, various years).

The Human Development Index (HDI) is a gender-neutral index of the basic capabilities in three dimensions of human development: the geometric mean of selected dimensions of health, education, and income. The Inequality-adjusted Human Development Index (IHDI) adjusts the HDI for inequality in each dimension across the entire population. Like HDI, it is calculated using 
the geometric mean but using inequality-adjusted dimension indices. The IHDI takes into account achievements in terms of health, education, and income by discounting each dimension's average value according to its level of inequality. Under perfect equality, HDI will equal IHDI. In cases of inequality, IHDI will fall below HDI. The difference between IHDI and HDI is the loss of human development due to inequality. IHDI is calculated for 145 countries by the UNDP. Life expectancy is distributed across a group of subjects with the same age, whereas years of schooling and income are distributed across individuals.

We use the following four steps to calculate the IHDI.

\section{Measuring Inequality in the Dimensions of the HDI}

The inequality measure, $\mathrm{A}$, is defined as $1-\frac{g}{\mu}$ where $\mathrm{g}$ is the geometric mean and $\mu$ is the arithmetic mean of the distribution. Symbolically,

$$
A_{x}=1-\frac{\sqrt[n]{X_{1} \ldots X_{n}}}{\bar{X}}
$$

$A_{x}$ for each variable (i.e., life expectancy, mean years of schooling, and disposable income per capita) is calculated separately. It is to be noted that negative and zero incomes are replaced by the minimum value of the bottom 0.5 percentile of the distribution.

\section{Adjusting the Dimension Indices for Inequality}

Symbolically, the inequality-adjusted dimension index of HDI ( $\left.I_{x}^{*}\right)$ is as follows:

$$
I_{x}^{*}=\left(1-A_{x}\right) \cdot I_{x}
$$

where $A_{x}$ is the corresponding inequality measure for different dimensions and $I_{x}$ is the HDI index without incorporating inequality. IHDI accounts for the full effect of income inequality.

\section{Combining the Dimension Indices to Get the Final IHDI}

IHDI is the geometric mean of the three dimension indices - education, health, and income per capita - and is represented symbolically as follows: 


$$
\begin{aligned}
& \text { IHDI }^{*}=\sqrt[3]{\left(I_{\text {Health }}^{*} \cdot I_{\text {Education }}^{*} I_{\text {Income }}^{*}\right)} \\
& \quad=\left(\sqrt[3]{\left[\left(1-A_{\text {health }}\right) \cdot\left(1-A_{\text {Education }}\right) \cdot\left(1-A_{\text {Income }}\right)\right]}\right) \cdot H D I
\end{aligned}
$$

The loss in HDI is calculated as follows:

$$
\text { Loss in HDI \% }=1-\left(\sqrt[3]{\left[\left(1-A_{\text {health }}\right) \cdot\left(1-A_{\text {Education }}\right) \cdot\left(1-A_{\text {Income }}\right)\right]}\right)
$$

The disadvantage of using IHDI is that it is not association sensitive and does not capture overlapping inequalities; therefore we should obtain the data from a single survey.

\section{Coefficient of Human Inequality}

The coefficient of human inequality is the weighted average of inequalities in health, education, and income and is given as follows:

$$
\text { Coefficient of human inequality }=\left(A_{\text {health }}+A_{\text {Education }}+A_{\text {Income }}\right) / 3
$$

When the values of $A_{\text {Education }}, A_{\text {Income }}$, and $A_{\text {health }}$ are comparable, loss in the HDI and the coefficient of human inequality are very close; when the inequalities differ in magnitude, the loss in the HDI tends to be higher than the coefficient of human inequality.

The Gender Inequality Index (GII) came into existence in 2010 for measuring the inequalities in gender development. Prior to the GII, the GDI was constructed in 1995 by the UNDP to measure gender development. The GDI used the same variables as HDI, but adjusted for the degree of disparity in achievement across genders. The average value of each of the component variables is substituted by "equally distributed equivalent achievements." The equally distributed equivalent achievement $\left(\mathrm{X}_{\text {ede }}\right)$ for a variable is taken as the level of achievement that, if attained equally by women and men, would be judged to be exactly as valuable socially as the actually observed disparate achievements. Lahiri, Chakraborty, and Bhattacharyya (2003) noted that taking an additively separable, symmetric, and constant elasticity marginal valuation function with an 
elasticity of 2 , the equally distributed equivalent achievement $\mathrm{X}_{\text {ede }}$ for any variable $\mathrm{X}$ turns out to be as follows:

$$
X_{\text {ede }}=\left[n_{f}\left(1 / X_{f}\right)+n_{m}\left(1 / X_{m}\right)\right]^{-1}
$$

where $X_{f}$ and $X_{m}$ are the values of the variable for females and males, and $n_{f}$ and $n_{m}$ are the population shares of females and males. $\mathrm{X}_{\text {ede }}$ is a "gender-equity-sensitive indicator" (GESI). Thus, for this chosen value of 2 for constant elasticity marginal valuation function, GDI is computed as follows:

$$
\mathrm{GDI}=\left\{\mathrm{L}_{\text {ede }}+\left(2 / 3 \times \mathrm{A}_{\text {ede }}+1 / 3 \times \mathrm{E}_{\text {ede }}\right)+\mathrm{Y}_{\text {ede }}\right\} / 3
$$

The GII, which replaced the GDI in 2010, reflects gender-based disadvantage mainly in three dimensions: reproductive health, proxied by the maternal mortality ratio (MMR) and adolescent fertility rate $(\mathrm{AFR})^{2}$; empowerment, as proxied by the share of parliamentary seats held across genders (PR) and attainment of secondary education (SE); and economic activity is proxied by the labor market participation rate (LFPR), which measures the participation of men and women in the market economy.

GII reflects the loss in development due to inequality across genders. An index of 0 implies women and men fare equally, whereas an index of 1 implies that one of the two genders fares as poorly as is possible. The first step in the calculation of GII involves treating zeros and extreme values (i.e., the outliers). GII is calculated by taking the geometric mean across the dimensions; because the geometric mean cannot be calculated for zero values, a minimum of 0.1 percent is set for all the components. The maximum value for the MMR is taken as 1,000 deaths per 100,000 births and minimum value is 10 per 100,000 births. A higher MMR suggests poor maternal health. After treating zeros, if any, we aggregate across dimensions within each gender group using geometric means. As the reproductive health variables are used, the aggregation formula for men and women is different.

\footnotetext{
${ }^{2}$ The MMR is defined as the number of female deaths per 100,000 live births annually, from any cause related to, or aggravated by, pregnancy or its management. AFR is the number of births per 1,000 women aged 15-19.
} 


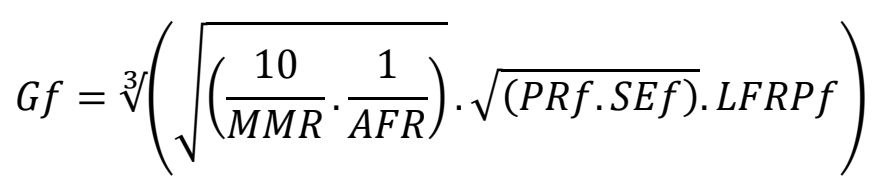

The rescaling by 0.1 is required to take into account the truncation of the maternal mortality ratio minimum at 10 .

For males, the formula is as follows:

$$
G m=\sqrt[3]{(1 \cdot \sqrt{(P R m \cdot S E m)} \cdot L F R P m)}
$$

Once the geometric mean of the three dimensions that determine the inequality index is taken, the next step is to aggregate across gender using the harmonic mean (HARM). The argument for using the HARM is that it captures the inequality between women and men and further adjusts for association between dimensions, but this method is open to criticism (Hawken and Munck 2012).

The HARM index is as follows:

$$
\operatorname{HARM}(G f, G m)=\left(\frac{\left((G f)^{-1}+(G m)^{-1}\right)}{2}\right)^{-1}
$$

Before calculating the final index, a composite index is calculated using the geometric means of the arithmetic means; this step is to give equal weights to both the genders. We then aggregate it across the various dimensions, i.e., health, empowerment, and economic activity.

The composite index is as follows:

$$
G(\bar{f}, \bar{m})=\sqrt[3]{(\text { Health }} \cdot \overline{\text { Empowerment }} \cdot \overline{L F P R})
$$


where

$$
\begin{aligned}
\overline{\text { Health }} & =\frac{\left(\sqrt{\left(\frac{10}{M M R} \cdot \frac{1}{A F R}\right)}+1\right)}{2} \\
\overline{\text { Empowerment }} & =\frac{(\sqrt{(P R f . S E f)}+\sqrt{(P R m . S E m)})}{2} \\
\overline{\text { LFPR }} & =\frac{(L F P R f+L F P R m)}{2}
\end{aligned}
$$

Symbolically, the GII is as follows:

$$
\mathrm{GII}=1-\frac{\operatorname{HARM}(G f, G m)}{G(\bar{f}, \bar{m})}
$$

The higher the value of GII, the higher the gender gap and the loss in potential of human development. Hence in order to utilize all our resources fully, we need to bridge this gender gap.

\section{CRITICAL ANALYSIS OF GII}

There are many conceptual and methodological problems associated with using GII for the measurement of gender inequality. There has been an ongoing debate on the choice of variables used for the formulation of gender indices. One of the main constraints in using the variables that completely capture the essence of the various dimensions is the lack of availability of sexdisaggregated data across the globe. Because the parameters are not the same in different nations and the scope of data collection also varies, it is very difficult to come up with variables that are uniform in all the nations. Hawken and Munck (2013) pointed out that data availability was not seen as a constraint for the construction of GII and that new data can be generated to measure certain indicators that are considered central to an index's overarching concept.

We argue that the assumptions and the choice of variables used to capture the dimensions - health, empowerment, and economic activity - in the GII remain inadequate and erroneous. One of the main drawbacks of using GII is that along with indicators of women vis-à-vis men, it also takes 
absolute indicators that are defined specifically for women (like MMR and AFR), which leads to conceptual problems in interpreting GII. In other words, taking only women-specific indicators leads to an index that measures women's well-being and status in the society whereas when we incorporate indicators comparable for men and women, we can construct a gender inequality measure that can be used to assess the relative well-being of women. As Permanyer (2013) points out, an increase in MMR and AFR systematically represents an increase in gender inequality levels while, on the other hand, decreases in women's education or LFPR do not necessarily represent a worse state of affairs as long as men's education and LFPR decrease by the same amount. Also, the corresponding value of MMR and AFR for men is taken as 1, which is far from realistic and leads to overestimation of the gap between women and men's health standards.

Yet another problem with using indicators like reproductive health is that it penalizes low-income countries, as health standards are usually low in developing countries. While the proponents of the index might rightly argue that it makes sense to penalize those countries with bad reproductive health conditions for women, it is fair to say that a country's performance in those areas is influenced by a myriad of factors other than gender-related issues (Permanyer 2013). This calls for variables that are broader and capture the health standards of both the sexes equally.

The flaw in the construction of GII with regard to an empowerment variable is that it only takes the share of women in the parliamentary seats at the national level and ignores women's representation in local governance and intrahousehold decision making. It is pertinent to incorporate variables like share of parliamentary seats in national and local levels of governance and percentage of women participating in intrahousehold decision making as a measure of empowerment. Along with indicators for education attainment and decision making, exposure to basic informational media like newspaper and television can be used as a variable to capture knowledge and networking for the measurement of empowerment across genders.

The third sub-indicator of the GII is LFPR, which measures the involvement of men and women in paid work. We know that housework, childcare, and care of elderly relatives represent women's unpaid work - which are an indispensable financial benefit to the entire economy (Bartuskova and Kubelkova 2014) - yet it fails to capture the care economy where women are typically overrepresented. Owing to the importance of unpaid work and the differences in representation of 
genders in Systems in National Accounts (SNA) and extended SNA (ext-SNA) activities, it is desirable to incorporate the unpaid work in the gender inequality index.

Integrating the care economy into GII has not happened even across countries with time use statistics. It is interesting to recall Becker (1965), in a paper titled "A Theory of Allocation of Time," published in the Economic Journal, where he noted that:

\begin{abstract}
throughout history the amount of time spent at work has never consistently been much greater than that spent at other activities. Economic development has led to a large secular decline in the work week so that today time spent at work is less than a third of the total time available. Consequently, the allocation and efficiency of "nonworking" time may now be more important to economic welfare than that of working time. Yet the attention paid by economists to the latter dwarfs any paid to the former.
\end{abstract}

The prime reasons for the lack of integrating time use statistics into GII are twofold. One, the time use survey itself is not conducted at a macro level in many developing countries. In many countries, the time series data of time use is unavailable. Two, the process of obtaining labor force participation statistics itself is highly partial as it does not incorporate unpaid care. Though the conceptual discussions on workforce participation highlighted the significance of giving thrust to the statistical invisibility of the unpaid care economy in framing the policies through integrating it in gender-related indices, it is not applied at empirical levels.

Time use statistics can be divided into three categories: SNA activities (that get included in GDP calculations), ext-SNA activities (that do not get included in GDP, but should be included in the satellite accounts), and residual non-SNA activities. A 1995 UNDP report presented that US\$16 trillion of global output is statistically invisible and within that, US\$11 trillion was the contribution of women to the unpaid care economy. The attempt of United Nations Statistical Division (UNSD) in extending the production boundary of the SNA in 1993 has led to the calculation of an ext-SNA in time use surveys and the integration of unpaid care work into the national accounting system as satellite accounts.

The time diary method is often used in preparing the time budget statistics. This method provides a retrospective chronological account of recent twenty-four-hour periods of the respondent's time 
use. Researchers then code the responses using a standard list of economic and non-economic activities. Researchers encountered two problems in valuing unpaid care work. One challenge was to get the economic activity in utils (i.e., units utilized) of time, while the second challenge was to impute the market price or market wages to time (Chakraborty 2014). Beneria and Feldman (1992) suggested that imputing price to time is an output method of valuing unpaid care, while imputing wages to time spent on unpaid care is an input method. Researchers encountered problems in getting the specified wage data and frequently used the lowest wage in the wage hierarchy in the market economy to valuate the unpaid care economy. We will consider the valuation estimates of the unpaid care economy in the GII estimate in the next section.

\section{CHOICE OF VARIABLES}

In this section, we discuss the variables used in the existing GII for capturing the three dimensions - health, empowerment, and economic activity — and their limitations, and suggest a new set of variables for computing GII. The existing GII variables and an alternative choice of variables for GII are collated in table 1.

While the HDI and GDI used life expectancy at birth for capturing health, the GII incorporated reproductive health variables, viz., MMR and AFR. The drawback of using life expectancy as an indicator of health is that it does not provide any information on the quality of life. AFR and MMR are also not appropriate as indicators of health when we are dealing with gender-based inequality, as they are defined specifically for women; when the corresponding value for men is taken as 1 , it can skew the results. Hence, we propose a more broad proxy for health that will capture the health of both the sexes equally - the under-five survival rates (USR) and healthy life expectancy (HALE) in years at birth.

The USR is defined as the probability per 1,000 that a newborn baby will survive until reaching age five (UN-IGME 2014). This is an important indicator as it captures gender discrimination in terms of access to health care and nutritional disadvantage. It is a biological advantage that girls have a better chance of survival at birth than boys; however this biological advantage is neutralized by gender discrimination. An excessive number of female deaths per thousand live births in spite 
of this biological advantage indicates some sort of gender bias in most of the countries and therefore is used as a proxy for health in the measurement of inequality.

Table 1. Choice of Variables for the Alternative Gender Inequality Index

\begin{tabular}{|c|c|c|}
\hline Dimension & GII : existing variables & Alternative GII variables \\
\hline \multirow[t]{2}{*}{ Health } & 1. Maternal Mortality Rate (MMR) & $\begin{array}{l}\text { 1. Under-five Survival Rate } \\
\text { (USR) }\end{array}$ \\
\hline & 2. Adolescent Fertility Rate (AFR) & $\begin{array}{l}\text { 2. Healthy Life Expectancy } \\
\text { (HALE) }\end{array}$ \\
\hline \multirow[t]{4}{*}{ Empowerment } & 1. Share of Parliamentary Seats (PR) & $\begin{array}{l}\text { 1. Share of Parliamentary Seats } \\
\text { at National and Sub-national } \\
\text { Levels (PRN and PRL) }\end{array}$ \\
\hline & $\begin{array}{l}\text { 2. Attainment of Secondary Education } \\
\text { (SE) }\end{array}$ & $\begin{array}{l}\text { 2. Attainment of Secondary } \\
\text { Education (SE) }\end{array}$ \\
\hline & & $\begin{array}{l}\text { 3. Intrahousehold Decision } \\
\text { making (IHDM) }\end{array}$ \\
\hline & & $\begin{array}{l}\text { 4. Share of women exposed to } \\
\text { knowledge media and networks } \\
\text { (NM) }\end{array}$ \\
\hline \multirow[t]{3}{*}{$\begin{array}{l}\text { Economic } \\
\text { Activity }\end{array}$} & $\begin{array}{l}\text { 1. Labor Market Participation Rates } \\
\text { (LFPR) }\end{array}$ & $\begin{array}{l}\text { 1. Labor Force Participation } \\
\text { Rates (LFPR) }\end{array}$ \\
\hline & & $\begin{array}{l}\text { 2. Contribution in Paid and } \\
\text { Unpaid Work }(\mathrm{T}) \text { in hours. }\end{array}$ \\
\hline & & 3. Wage Rate (W) \\
\hline
\end{tabular}

The USR is calculated by subtracting the number of deaths per 1,000 before the age of five. We have chosen the USR in place of under-five mortality rates because the under-five mortality rate is an example of a negative indicator. A higher mortality rate signifies a lower level of health standards and hence lower welfare. For all the other indicators we have used, a higher value always signifies higher welfare, hence we incorporate the USR for uniformity.

The rationale for using HALE in place of life expectancy is that it is adjusted to represent the average number of years an individual lives in "full health." In that sense, it represents the quality of health care facilities across countries. The difference in HALE should give some idea about the 
standard of health care facilities across all the countries and across gender. The data for HALE is organized from UN data for the year 2012. ${ }^{3}$ HALE is much less than life expectancy for almost all Asia-Pacific nations, indicating a lack of health facilities and a difference in access to these facilities across genders. The difference in life expectancy across gender also indicates a wide gap in access to health facilities across genders.

Empowering women and encouraging them to participate in economic life is essential for equity and efficiency. Given the complexity of its definition, it is not an easy task to measure the concept of "empowerment." The indicators used for this analysis are attainment of secondary education, representation at national and local levels of government, intrahousehold decision making, and a proxy for the number of women exposed to knowledge media and networks. Considering that data collection methods are not uniform across different nations, the proxy used for these indicators might be different or, in some cases, absent. Therefore we compare only India and New Zealand to study the variation in inequality standards due to these indicators of knowledge media and networking.

The variables related to intrahousehold decision making and the share of women exposed to knowledge media and networks are organized from latest round of National Family Health Survey (NFHS) conducted in India. According to the report, only 37 percent of women participate in decision making related to matters like health care, large household purchases, making purchases for daily household needs, and visiting family or relatives. Also, only 65 percent of women are exposed to knowledge and media networks like newspapers, magazines, television, radio, or cinema as opposed to 82 percent of males who have access to these.

The assumption we used to compute the intrahousehold decision-making variable is that the share of men participating in intrahousehold decision making is 100 percent. This is because even in households (India) where women participate in decision making, there is no decision for which a majority of the currently married women are the sole decision makers. Only 15 percent of women have a savings account that they use themselves. The intrahousehold decision-making variable is thus constructed based on the survey by NFHS, where they asked married women whether they are

\footnotetext{
${ }^{3}$ Available at:

http://data.un.org/Data.aspx?q=life+expectancy\&d=WHO\&f=MEASURE_CODE\%3AWHOSIS_000002
} 
allowed to make their own decisions on health care, large household purchases, daily household needs, and visiting their family or relatives.

While comparing the empowerment variable in other countries, a similar dimension might not be available due to the differences in methods of conducting surveys, but we use a close approximation. For instance, in India, the share of parliamentary seats for women at the local level is assumed to be 33 percent; while for New Zealand the share of parliamentary seats for women at the local level is 33 percent for city council, 37 percent for community board, 30 percent district council, and 21 percent regional council. We take the average of these values and get women's share in local government in New Zealand as of 2013 as 30.25 percent. The data is organized from the Department of Internal Affairs-local election statistics, New Zealand. ${ }^{4}$

The representation of women and men in different tiers of government is used as a variable for empowerment because such positions give them great opportunity to influence government policies and participate in the decision making of Parliament. But representation at national levels cannot alone capture decision-making power and we have therefore incorporated representation at local levels. This is based on the belief that women's participation at some level of politics will positively affect the future political activity of other women (Bartuskova and Kubelkova 2014).

The GII used the LFPR for the measurement of economic activity. A higher LFPR leads to economic and financial independence. Though a very important indicator, it ignores the contributions of women in unpaid work and leads to undervaluation. It also ignores the wage gap between women and men for equal work. We therefore incorporate the measurement of the care economy sectors in the index of gender inequality using "time use surveys." In order to get wage differentials, we take the mean monthly earrings of employees from ILO database for various sectors and then take its contribution based on the contribution of that sector to the GDP of the nation (i.e., 17 percent agriculture, 26 percent industry, and 57 percent service sector in case of India). For all other Asia-Pacific countries, data is taken from HDR reports.

The valuation of the unpaid care economy is based on shadow pricing the agricultural wage for India and New Zealand. It is to be noted that time use surveys are conducted by different agencies

\footnotetext{
${ }^{4}$ Available at: http://www.stats.govt.nz/browse_for_stats/snapshots-of-nz/nz-socialindicators/Home/Trust $\% 20$ and $\% 20$ participation $\% 20 \mathrm{in} \% 20$ government/female-rep-parl-local-govt.aspx
} 
in different countries, hence the choice of activities selected for their ext-SNA might be a little different; therefore the figures for different countries on unpaid care economy might not be fully comparable.

The data paucity thwarts us from including more countries with a complete set of variables; however, we computed the GII using an alternative methodology for 24 countries in the AsiaPacific region, using a subset of new variables suggested where data is available. For illustration, we have computed GII using all the variables we have suggested, however we are limited to New Zealand and India due to data constraints.

\section{CONSTRUCTING GII USING THE NEW CHOICE OF VARIABLES}

In this section, we construct GII using the new set of variables and compare it with the existing GII. The dimensions used for our construction remain the same as the UNDP GII-health, empowerment, and economic activity-however, we shall be proposing an alternative set of variables in constructing the GII, as indicated in table 1 . We use the same achievement matrix (using new variables) for the calculation of GII as used by the UNDP and study the gap between the two values. The aggregation methodology used for the calculation of the new GII is also the same. Incorporating these variables, we can better account for gender inequality indicated by the difference in the two values.

GII reflects gender-based disadvantage mainly in three dimensions - health, empowerment, and economic activity. Before aggregating the variables across dimensions within each gender group, we calculate the separate indices for the three dimensions using the new variables:

$$
\begin{gathered}
\text { Health }=\sqrt{U S R_{f} \cdot H A L E_{f}} \text { and } \sqrt{U S R_{m} \cdot H A L E_{m}} \\
\text { Empowerment }=\sqrt[3]{\left(\sqrt{P R_{N f} \cdot P R_{L f}}\right) \cdot S E_{f} \cdot N M f \cdot I H D M_{f}} \text { and } \\
\sqrt[3]{\left(\sqrt{\left.P R_{N m} \cdot P R_{L m}\right) \cdot S E_{m} \cdot N M m \cdot I H D M_{m}}\right.}
\end{gathered}
$$




$$
\text { Economic Activity }=\left(\frac{L F P R_{f} \cdot T_{M f}}{1 \cdot T_{C f}}\right) * \ln \left(W_{f}\right) \text { and }\left(\frac{L F P R_{m} \cdot T_{M m}}{1 \cdot T_{C m}}\right) * \ln \left(W_{m}\right)
$$

After constructing the separate indices for men and women, we aggregate them across dimensions within each gender group using geometric means as suggested by the UNDP.

For females, it is given by:

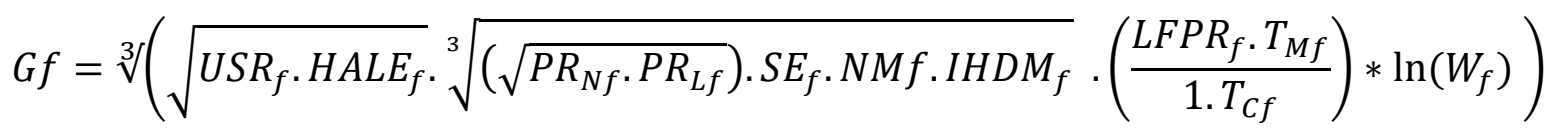

and for males, it is given by:

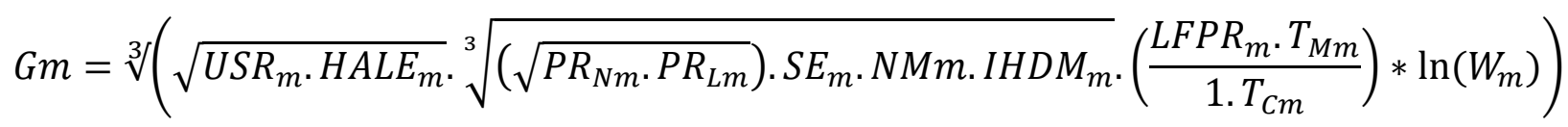

The next step is aggregating across genders using HARM to adjust for the association between dimensions.

The index is:

$$
\operatorname{HARM}(G f, G m)=\left(\frac{\left((G f)^{-1}+(G m)^{-1}\right)}{2}\right)^{-1}
$$

For giving equal weights to both the genders, we take the arithmetic mean and then aggregate it across dimensions given by:

$$
G(\bar{f}, \bar{m})=\sqrt[3]{(\text { Health }} \cdot \overline{\text { Empowerment }} \cdot \overline{L F P R})
$$

where 


$$
\overline{\text { Health }}=\frac{\left(\sqrt{U S R_{f} \cdot H A L E_{f}}+\sqrt{U S R_{m} \cdot H A L E_{m}}\right)}{2}
$$

$$
\begin{aligned}
& \overline{\text { Empowerment }} \\
& =\frac{\left(\sqrt[3]{\left(\sqrt{P R_{N f} \cdot P R_{L f}}\right) \cdot S E_{f} \cdot N M f \cdot I H D M_{f}}+\sqrt[3]{\left(\sqrt{P R_{N m} \cdot P R_{L m}}\right) \cdot S E_{m} \cdot N M m \cdot I H D M_{m}}\right)}{2} \\
& \overline{L F P R}=\frac{\left(\left(\frac{L F P R_{f} \cdot T_{M f}}{1 \cdot T_{C f}}\right) * \ln \left(W_{f}\right)+\left(\frac{L F P R_{m} \cdot T_{M m}}{1 . T_{C m}}\right) * \ln \left(W_{m}\right)\right)}{2}
\end{aligned}
$$

\begin{tabular}{|c|c|c|c|c|}
\hline & \multicolumn{4}{|l|}{ Health } \\
\hline & \multicolumn{2}{|l|}{ USR } & \multicolumn{2}{|c|}{ HALE } \\
\hline Male & \multicolumn{2}{|l|}{0.949} & \multicolumn{2}{|c|}{56} \\
\hline Female & \multirow{2}{*}{\multicolumn{2}{|c|}{0.945}} & \multicolumn{2}{|c|}{59} \\
\hline \multirow[t]{3}{*}{$(\mathrm{F}+\mathrm{M}) / 2$} & & & 7.37 & \\
\hline & \multicolumn{4}{|c|}{ Empowerment } \\
\hline & $\mathbf{P R}_{\mathbf{N}}$ & $\mathbf{P R}_{\mathrm{L}}$ & SE & NM \\
\hline Male & 0.891 & 0.67 & 0.504 & 0.61 \\
\hline Female & 0.109 & 0.33 & 0.266 & 0.39 \\
\hline \multirow[t]{3}{*}{$(\mathrm{F}+\mathrm{M}) / 2$} & 0.494 & & & \\
\hline & \multicolumn{4}{|c|}{ Economic Activity } \\
\hline & LFPR & $\mathbf{T}_{\mathbf{M}}$ & $\mathbf{W}_{M}(\ln )$ & $\mathbf{T}_{\mathbf{C}}$ \\
\hline Male & 0.809 & 6.51 & 8.966 & 0.86 \\
\hline Female & 0.288 & 3.08 & 7.73 & 5.86 \\
\hline$(\mathrm{F}+\mathrm{M}) / 2$ & 28.035 & & & \\
\hline
\end{tabular}

Finally, GII is given by:

$$
\mathrm{GII}=1-\frac{\operatorname{HARM}(G f, G m)}{G(\bar{f}, \bar{m})}
$$

Table 2. GII with New Variables: Illustrative Estimates

Source: (Basic data), UNDP 2015 
Table 2 provides the illustrative estimates for India using the methodology and choice of variables suggested above. Incorporating these variables, we get the new value of the GII for India as 0.5168. Hence our assumption that the former GII overestimates the gap between the two genders was correct and we can say that using women-specific indicators leads to an erroneous estimation of gender inequality.

Table 3. Comparing GII Values: Illustrative Estimates

\begin{tabular}{lll}
\hline Country & Existing GII & GII (with new choice of variables) \\
\hline India & 0.61 & 0.5168 \\
\hline
\end{tabular}

Source: (Basic data), UNDP 2015

The GII has been constructed to satisfy the assumption of symmetry in gender gaps. It means that the direction of the gender gaps, whether they favor women or men, is not taken into account. For example, an index of 0.61 or 0.51 (table 3 ) does not specify if the situations are in favor of men or advantageous to women. These estimates should be read with caution and should not be used for policy formulations. This demonstrates the need for decomposed indices so that we can interpret the direction of the inequality in various dimensions, but it has several limitations in terms of decomposing it into subcomponents and cannot be used for interpretation and policy recommendations. We therefore suggest a decomposed index that can be used to study the direction of gender gaps and can be used for detailed exploration of the internal structure of the index, which we attempt in section $\mathrm{V}$.

\section{CONSTRUCTING A DECOMPOSED INDEX}

A few technical problems were identified in section III while constructing the GII, its functional form, choice of variables, and interpretation of the final index. We therefore suggest a decomposed index that is easy to interpret and can be used to study the direction of gender gaps. Permanyer (2013) also pointed out the importance of a decomposed index saying it is useful for a precise and detailed exploration of the internal structure of the index and contributes to transparency. A similar functional form was used in Permanyer (2010), Beneria and Permanyer (2010), and Klasen and Schüler (2011). 
The functional form we suggest is as follows:

$$
G R S=\prod_{i=1}^{n}\left(\frac{x_{i}}{y_{i}}\right)^{w_{i}}
$$

Men are better off $\longleftrightarrow 1 \longrightarrow$ Women are better off

$x_{i}$ and $y_{i}$ denote the average women's and men's achievement levels in indicator $i$ for $n$ given indicators; $\Pi$ denotes multiplication; and $w_{i}$ are the weights given to the indicator $i$. The weights represent the relative importance of an indicator with respect to others. The interpretation of the Gender-relative Status Index (GRS) is simple: Whenever GRS $>1$, women are on an average better off than men and when GRS $<1$, men fare better than women on average. It has the further advantage of being decomposable by dimensions to see how genders are doing across various dimensions. We propose that we use this functional form for a composed index that will give the aggregate value of GII and three decomposed indices for each of the dimensions to study the relative achievements of genders in health, empowerment, and economic activity separately.

A range of statistical procedures have been developed in order to ascertain an appropriate weighing scheme. One of those is Principal Component Analysis (PCA), which we will attempt in section VI. However in this section, we theoretically categorized weights as used by HDI, GEM, and many other socioeconomic indices. We divide our indicators into three component areashealth, empowerment, and economic activity. While each of the three main dimensions has equal weight in producing the final index score, each indicator within them does not. We use geometric means for aggregation across dimensions and indicators for a given dimension also. This analysis is carried out for Asia-Pacific economies that have completed time use surveys. As the proxy for intrahousehold decision making is different in various countries and not available for all the countries, we exclude this variable for now. The new GII is represented as follows:

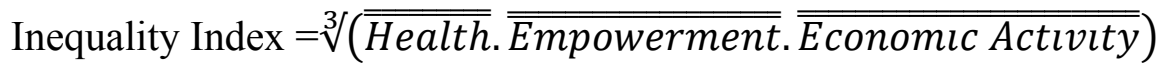


where

$$
\begin{aligned}
\overline{\overline{\text { Health }}} & =\sqrt{\frac{H A L E_{f}}{H A L E_{m}} \cdot \frac{U S R_{f}}{U S R_{m}}} \\
\overline{\overline{\text { Empowerment }}} & =\sqrt[3]{\sqrt{\frac{P R_{N f}}{P R_{N m}} \cdot \frac{P R_{L f}}{P R_{L m}} \cdot \frac{S E_{f}}{S E_{m}} \cdot \frac{N M_{f}}{N M_{m}}}} \\
\overline{\overline{\text { Economıc Actıvity }}} & =\left(\frac{L F P R_{f} \cdot T_{M f} \cdot \ln \left(W_{M f}\right)}{L F P R_{m} \cdot T_{M m} \cdot \ln \left(W_{M m}\right)}\right) \cdot\left(\frac{T_{C m}}{T_{C f}}\right)
\end{aligned}
$$

Using these intermediate indices, we get a total of four indices that can interpret the relative achievement levels of men and women for each component (at disaggregate levels) and in aggregate terms. From the formulae used above, it is clear that all the variables have different weights in the composite index. While HALE and USR have weights of one-sixth each; SE and NM (access to knowledge and media) have weights of one-ninth, and PR at national and local levels together contribute to one-ninth of the total index.

Similarly, LFPR, when multiplied with wage and time, measures the value of the market economy and the contribution of both the genders to the market economy. It is assumed that males and females "participate" in the ext-SNA activities, however small the contribution might be in case of men. The compensation for ext-SNA activities is assumed to be the agricultural wage. Before calculating the indices, the variables are normalized using the $\frac{\text { value-min }}{\max -\min }$ approach so that all the values lie in the range of 0 and 1.

The valuation for ext-SNA (SNA 1993) activities is carried out using the global substitute method of using the lowest wage in the wage hierarchy in the market economy. The data was not ready to use the "specialized wage substitute method" to value the unpaid care sector; therefore using these intermediate indices, we get a total of four indices that can interpret the relative achievement levels of men and women in disaggregate and in aggregate terms. From the formulae used above, it is clear that all the variables have different weights in the composite index. HALE and USR have weights of one-sixth each; SE, NM, and IHDM (intrahousehold decision making) have weights of 
one-twelfth; and PR at national and local levels together contribute to one-twelfth of the total index.

Table 4. Impact of Variables-Scenario 1

\begin{tabular}{lllll}
\hline Country & Composite GII & $\begin{array}{l}\text { Composite GII } \\
\text { without U5SR }\end{array}$ & $\begin{array}{l}\text { Rank (Composite } \\
\text { GII) }\end{array}$ & New Rank \\
\hline \hline Australia & 0.5707 & 0.5746 & 3 & 3 \\
India & 0.2119 & 0.2139 & 10 & 10 \\
China & 0.5158 & 0.5181 & 5 & 5 \\
New Zealand & 0.5875 & 0.5901 & 2 & 2 \\
Japan & 0.3081 & 0.3122 & 8 & 8 \\
Pakistan & 0.1319 & 0.1322 & 11 & 7 \\
Korea & 0.3620 & 0.3662 & 7 & 6 \\
Bangladesh & 0.4631 & 0.4651 & 6 & 9 \\
Cambodia & 0.3044 & 0.3072 & 9 & 1 \\
Thailand & 0.6224 & 0.6315 & 1 & 4 \\
Mongolia & 0.5559 & 0.5655 & 4 & \\
\hline \hline
\end{tabular}

Source: (Basic data), UNDP 2015

To study the impact of each variable separately, we compare the ranks of countries with new GII and without a particular target variable. We study the impact of not including a specific variable on the composite index and the ranks of various countries. As can be inferred from table 4, the value of GII and ranks remain almost the same even if we ignore the USR. Because GII is a relative index for measuring and comparing gender disparity, we can say that it does not have a very significant effect on the rankings of various countries, but one cannot deny the relevance of this variable in studying the health dimension of gender inequality.

Table 5. Impact of Variables-Scenario 2

\begin{tabular}{lllll}
\hline Country & Composite GII & $\begin{array}{l}\text { Composite GII } \\
\text { without HALE }\end{array}$ & $\begin{array}{l}\text { Rank } \\
\text { (Composite GII) }\end{array}$ & New Rank \\
\hline \hline Australia & 0.5707 & 0.567 & 3 & 3 \\
India & 0.2119 & 0.210 & 10 & 10 \\
China & 0.5158 & 0.513 & 5 & 5 \\
New Zealand & 0.5875 & 0.585 & 2 & 2 \\
Japan & 0.3081 & 0.304 & 8 & 8 \\
Pakistan & 0.1319 & 0.132 & 11 & 71 \\
Korea & 0.3620 & 0.358 & 7 & 6 \\
Bangladesh & 0.4631 & 0.461 & 6 & 9 \\
Cambodia & 0.3044 & 0.302 & 9 & 1 \\
Thailand & 0.6224 & 0.613 & 1 & 4 \\
Mongolia & 0.5559 & 0.546 & 4 & \\
\hline
\end{tabular}

Source: (Basic data), UNDP 2015 
Omitting HALE from GII calculation, we see that GII falls for every country, implying that the GII worsens after taking into account this variable (table 5). This means that after taking into account HALE, the inequality among men and women increases further, which can be attributed to the access to health care facilities in different countries. Although the value of the GII increases, we should note that the ranks do not change and hence it does not change the order in which countries lie on the gender equality graph.

Table 6. Impact of Variables-Scenario 3

\begin{tabular}{lllll}
\hline Country & Composite GII & $\begin{array}{l}\text { Composite GII } \\
\text { without } \text { PR }_{\mathbf{L}}\end{array}$ & $\begin{array}{l}\text { Rank } \\
\text { (Composite GII) }\end{array}$ & New Rank \\
\hline Australia & 0.5707 & 0.572 & 3 & 3 \\
India & 0.2119 & 0.196 & 10 & 10 \\
China & 0.5158 & 0.519 & 5 & 5 \\
New Zealand & 0.5875 & 0.592 & 2 & 2 \\
Japan & 0.3081 & 0.306 & 8 & 9 \\
Pakistan & 0.1319 & 0.127 & 11 & 11 \\
Korea & 0.3620 & 0.358 & 7 & 6 \\
Bangladesh & 0.4631 & 0.453 & 6 & 8 \\
Cambodia & 0.3044 & 0.312 & 9 & 1 \\
Thailand & 0.6224 & 0.634 & 1 & 4 \\
Mongolia & 0.5559 & 0.541 & 4 & \\
\hline \hline
\end{tabular}

Source: (Basic data), UNDP 2015

The ranks for Cambodia and Japan switch after excluding representation of women in local governance (table 6). Also, the inequality index falls for some countries, while it increases for others.

Excluding the share of women with access to knowledge networks leads to a worsening of the index for most of the countries, implying that the percentage of women with access to these networks is improving with time. The ranks of some countries also change as a result of the omission of this variable (table 7). 
Table 7. Impact of Variables-Scenario 4

\begin{tabular}{lllll}
\hline Country & Composite GII & $\begin{array}{l}\text { Composite GII } \\
\text { without NM }\end{array}$ & $\begin{array}{l}\text { Rank } \\
\text { (Composite GII) }\end{array}$ & New Rank \\
\hline Australia & 0.5707 & 0.543 & 3 & 3 \\
India & 0.2119 & 0.199 & 10 & 10 \\
China & 0.5158 & 0.481 & 5 & 5 \\
New Zealand & 0.5875 & 0.562 & 2 & 1 \\
Japan & 0.3081 & 0.278 & 8 & 9 \\
Pakistan & 0.1319 & 0.130 & 11 & 71 \\
Korea & 0.3620 & 0.332 & 7 & 6 \\
Bangladesh & 0.4631 & 0.450 & 6 & 8 \\
Cambodia & 0.3044 & 0.290 & 9 & 2 \\
Thailand & 0.6224 & 0.557 & 1 & 4 \\
Mongolia & 0.5559 & 0.507 & 4 & \\
\hline
\end{tabular}

Source: (Basic data), UNDP 2015

Table 8. Impact of Variables-Scenario 5

\begin{tabular}{lllll}
\hline Country & Composite GII & $\begin{array}{l}\text { Composite GII } \\
\text { without Wage }\end{array}$ & $\begin{array}{l}\text { Rank } \\
\text { (Composite GII) }\end{array}$ & New Rank \\
\hline \hline Australia & 0.5707 & 0.576 & 3 & 3 \\
India & 0.2119 & 0.223 & 10 & 10 \\
China & 0.5158 & 0.524 & 5 & 5 \\
New Zealand & 0.5875 & 0.594 & 2 & 2 \\
Japan & 0.3081 & 0.316 & 8 & 8 \\
Pakistan & 0.1319 & 0.140 & 11 & 7 \\
Korea & 0.3620 & 0.369 & 7 & 6 \\
Bangladesh & 0.4631 & 0.475 & 6 & 9 \\
Cambodia & 0.3044 & 0.308 & 9 & 1 \\
Thailand & 0.6224 & 0.628 & 1 & 4 \\
Mongolia & 0.5559 & 0.562 & 4 & \\
\hline
\end{tabular}

Source: (Basic data), UNDP 2015

There is no effect on the rankings of various countries if we omit the wage variable in the economic activity dimension, but the value of the index differs from the original value (table 8). 
Table 9. Impact of Variables-Scenario 6

\begin{tabular}{lllll}
\hline Country & Composite GII & $\begin{array}{l}\text { Composite GII } \\
\text { without Time Use }\end{array}$ & $\begin{array}{l}\text { Rank } \\
\text { (Composite GII) }\end{array}$ & New Rank \\
\hline Australia & 0.5707 & 0.841 & 3 & 2 \\
India & 0.2119 & 0.516 & 10 & 10 \\
China & 0.5158 & 0.780 & 5 & 4 \\
New Zealand & 0.5875 & 0.856 & 2 & 1 \\
Japan & 0.3081 & 0.687 & 8 & 8 \\
Pakistan & 0.1319 & 0.461 & 11 & 6 \\
Korea & 0.3620 & 0.718 & 7 & 7 \\
Bangladesh & 0.4631 & 0.697 & 6 & 9 \\
Cambodia & 0.3044 & 0.666 & 9 & 5 \\
Thailand & 0.6224 & 0.750 & 1 & 3 \\
Mongolia & 0.5559 & 0.808 & 4 & \\
\hline \hline
\end{tabular}

Source: (Basic data), UNDP 2015

As can be inferred from the table 9, the rankings of various countries change significantly if we omit the time use variable that takes into account the care economy and unpaid sector. Also, the value of the index changes drastically without the time use component.

We can therefore conclude that all the variables have an effect on the value and rankings of various countries and, when taken together, can affect the world rankings of different countries significantly.

The value of decomposed and composite indices for India and New Zealand are given in the table 10. These values can be used for better interpretation and formulation of future policies.

Table 10. GII, Decomposed Indices: Illustrative Estimates for India and New Zealand

\begin{tabular}{lllll}
\hline \hline Country & Health Index & $\begin{array}{l}\text { Empowerment } \\
\text { Index }\end{array}$ & $\begin{array}{l}\text { Economic } \\
\text { Activity Index }\end{array}$ & $\begin{array}{l}\text { Composite } \\
\text { Index } \\
\text { (Gender } \\
\text { Inequality } \\
\text { Index) }\end{array}$ \\
\hline \hline India & 1.0242 & 0.4359 & 0.0213 & 0.2119 \\
New Zealand & 1.0144 & 0.7618 & 0.2623 & 0.5874 \\
\hline \hline
\end{tabular}

Source: Authors' computations

As we compare the value for India and New Zealand (table 10), we notice that New Zealand's women are better off than women in India in all three dimensions of health, empowerment, and economic activity. While they are also doing better than men in terms of health, the gap between 
the achievement levels of men and women is also not very significant in terms of empowerment and opportunities. In terms of economic activity, wage gap, and unpaid work, women still lag far behind men and there is a need for policies to account for this unpaid work. On the other hand, India is far worse than New Zealand in terms of labor force participation, economic activity, and the empowerment index. This implies that to bridge this gender gap India requires more policies to involve women in decision making and in the market economy with equal opportunities and equal pay for the work done.

\section{CONSTRUCTING THE GII USING PRINCIPAL COMPONENTS ANALYSIS (PCA)}

Gender inequality is a multidimensional concept that cannot be quantified easily, as it is a process determined by the interaction of multiple variables. We use principal components estimation to assign weights and estimate the relevant components to construct the GII.

The weight assigned to the variables is significant for maximizing information from the data to incorporate in the index construction. We collated the data of causal variables of gender inequalities. Each causal variable relates to a particular dimension of gender inequality. In the first stage, the data is trichotamized into three dimensions: health, empowerment, and labor force participation, which defines gender inequality. The variables in these three components may contain significant correlation. The final issue is how to aggregate over the range of different variables to derive a unidimensional measure of gender inequality.

We use Principal Component Analysis (PCA) for assigning weights to different variables. PCA is a multivariate statistical technique used to reduce the number of variables in the data set into a smaller number of dimensions. PCA creates uncorrelated indices where each component is a linear weighted combination of the initial variables. The weights for each of the principal components are given by the eigen vectors of the correlation matrix. The variance for each of the principal components is explained by the eigen value $(\lambda)$ of the corresponding eigen vector. In other words, the eigen values are the variances of the principal components. The components are ordered so that the first component (PC1) explains the largest possible amount of variation in the original data. As the sum of the eigen values equals the number of variables in the initial data set, the proportion of the total variation in the original data set accounted for by each principal component is given by $\lambda$ 
$\mathrm{i} / \mathrm{n}$. The second component (PC2) is completely uncorrelated with the first component, and explains additional but less variation. Each component captures an additional dimension in the data, while explaining smaller and smaller proportions of the variation of the original variables. The number of principal components extracted is usually decided on by the user and usually the components with an eigen value of greater than one are selected for consideration.

As we can see from the table 11, the first principal component has maximal overall variance. The second principal component has maximal variance among all unit length linear combinations that are uncorrelated to the first principal component. All nine components combined contain the same information as the original variables, but the important information is partitioned over the first three components because they explain roughly 85 percent of the total variance; therefore we can say that PCA is just a linear transformation of the data. The PCA shows two panels. The first panel shows the eigen values of the correlation matrix in decreasing order. The corresponding eigen vectors are listed. The eigen values are the variances of the principal components, therefore we can say that the first principal component explains 46.895 percent of the total variance and the second component explains 22.60 percent of the total variance.

Table 11. PCA Eigen Values and Cumulative Estimates

\begin{tabular}{lrccc}
\hline Comp & Eigenvalue & Difference & Proportion & Cumulative \\
\hline Comp1 & 4.22011 & 2.18654 & 0.4689 & 0.4689 \\
Comp2 & 2.03357 & .704314 & 0.2260 & 0.6949 \\
Comp3 & 1.32926 & .625078 & 0.1477 & 0.8425 \\
Comp4 & .704181 & .302355 & 0.0782 & 0.9208 \\
Comp5 & .401826 & .187182 & 0.0446 & 0.9654 \\
Comp6 & .214644 & .155674 & 0.0238 & 0.9893 \\
Comp7 & .0589702 & .0289046 & 0.0066 & 0.9958 \\
Comp8 & .0300657 & .0226949 & 0.0033 & 0.9992 \\
Comp9 & .00737078 &. & 0.0008 & 1.0000 \\
\hline \hline
\end{tabular}

Source: (Basic data), UNDP 2015

We can say that these three components (PC1, PC2, and PC3) contain roughly 84 percent of the total information (table 11). As the first three components explain the maximum variance in the data, we can list just these components as shown in table 12 . 
For these principal components we take the value 0.3 as the threshold. In our estimation, the first component is sensitive towards secondary education, exposure to knowledge networks, labor force participation, wage, and time use data. ${ }^{5}$ This implies that nearly 46 percent of the information is sensitive to these variables. Similarly PC2 is sensitive to USR, HALE, and share of parliamentary seats at national and local levels. Therefore PCA helps us determine the weights of each of the variables and dimensions and its effect on the index. Based on PCA, the index for the selected 11 countries is given in table 12 .

Table 12. Construct 1: Composite GII using PCA

\begin{tabular}{lllll}
\hline Country & PC1 & PC2 & PC3 & $\begin{array}{l}\text { Composite } \\
\text { Index }\end{array}$ \\
\hline Australia & 1.6810 & -0.4146 & 0.3366 & 0.8992 \\
India & 1.0261 & -0.5547 & 0.5062 & 0.5170 \\
China & 1.5623 & -0.5242 & 0.3904 & 0.8111 \\
New & 1.6962 & -0.3579 & 0.3496 & 0.9252 \\
Zealand & & & & \\
Japan & 1.5023 & -0.7260 & 0.2445 & 0.6990 \\
Pakistan & 0.8444 & -0.4697 & 0.6692 & 0.4631 \\
Korea & 1.4686 & -0.6417 & 0.3283 & 0.7162 \\
Bangladesh & 1.3685 & -0.5277 & 0.4938 & 0.7169 \\
Cambodia & 1.1997 & -0.6559 & 0.6946 & 0.6192 \\
Thailand & 1.7308 & -0.6943 & 0.2967 & 0.8460 \\
Mongolia & 1.7293 & -0.6512 & 0.2192 & 0.8440 \\
\hline Source (Basic
\end{tabular}

Source: (Basic data), UNDP 2015

The criteria for selecting the countries in the Asia-Pacific region was the availability of data.

Construct 1 incorporated all GII variables we have chosen (table 12), while due to data constraints construct 2, with a larger set of countries, excluded variables related to time use, exposure to knowledge services, and feminization of governance at local level (table 13).

\footnotetext{
5 The correlation matrices of construct 1 and 2, as well as the eigen values of construct 2 are not given in the paper; they are available on request.
} 
Table 13. Construct 2: Composite GII Using PCA

\begin{tabular}{|c|c|c|c|c|}
\hline Country & PC1 & PC2 & PC3 & $\begin{array}{l}\text { Composite } \\
\text { Index }\end{array}$ \\
\hline Australia & 1.4196 & 0.8133 & -0.1626 & 0.8711 \\
\hline India & 1.0624 & 0.5029 & -0.3921 & 0.5575 \\
\hline China & 1.4081 & 0.6832 & -0.249 & 0.8077 \\
\hline New Zealand & 1.4289 & 0.8052 & -0.1132 & 0.8849 \\
\hline Japan & 1.3046 & 0.8475 & -0.3952 & 0.7714 \\
\hline Pakistan & 1.0107 & 0.4041 & -0.2998 & 0.5263 \\
\hline Korea & 1.325 & 0.7388 & -0.3437 & 0.7619 \\
\hline Bangladesh & 1.3085 & 0.661 & -0.2991 & 0.7421 \\
\hline Cambodia & 1.4752 & 0.4491 & -0.3195 & 0.7554 \\
\hline Thailand & 1.4086 & 0.7579 & -0.3452 & 0.8068 \\
\hline Mongolia & 1.4198 & 0.8638 & -0.3582 & 0.8396 \\
\hline Indonesia & 1.2607 & 0.6878 & -0.313 & 0.7238 \\
\hline Lao People's Dem. Rep & 1.5146 & 0.5498 & -0.2321 & 0.8238 \\
\hline Malaysia & 1.2427 & 0.7546 & -0.3635 & 0.7227 \\
\hline Myanmar & 1.5496 & 0.8325 & -0.4586 & 0.8686 \\
\hline Nepal & 1.4384 & 0.4346 & -0.0976 & 0.7861 \\
\hline Papua New Guinea & 1.5034 & 0.4683 & -0.4744 & 0.7377 \\
\hline Philippines & 1.2954 & 0.8719 & -0.1985 & 0.8205 \\
\hline Singapore & 1.3663 & 0.7564 & -0.237 & 0.8118 \\
\hline Vietnam & 1.4601 & 0.7478 & -0.2372 & 0.8539 \\
\hline Bhutan & 1.4405 & 0.7886 & -0.4363 & 0.8093 \\
\hline Kazakhstan & 1.4372 & 0.8677 & -0.3167 & 0.8588 \\
\hline Sri Lanka & 1.1488 & 0.8102 & -0.4432 & 0.6752 \\
\hline
\end{tabular}

Source: (Basic data), UNDP 2015

The results revealed that the UNDP GII overestimates the gap between the two genders and found that using women-specific indicators leads to an erroneous estimation of gender inequality. One of the major findings is that incorporating time use leads to a shift in the rankings of various countries. Because women are disproportionately overrepresented in ext-SNA activities, and if we take their contribution into account, many countries like Thailand and Mongolia fare really well 
when it comes to gender equality. Singapore, Japan, and Korea are a few examples where the inequality index worsens after taking into account the unpaid care economy. India and Pakistan still remain the countries with the most disparity even after incorporating time use and exposure to other services. The rank of Pakistan falls further after taking into account wage differentials. In some cases (like Myanmar) where women outperform men in most of the indicators, only the share of parliamentary seats (a crucial indicator for studying gender inequality) leads to its lower rankings among other Asia-Pacific countries. Singapore, with an overall rank of 15, as suggested by HDR, falls significantly after taking into account the wage gap. It is way behind countries like Bhutan, Viet Nam, Cambodia, Nepal, and China.

Figure 1. Comparison of Ranks Using Different Functional Form, Variables, and Weights

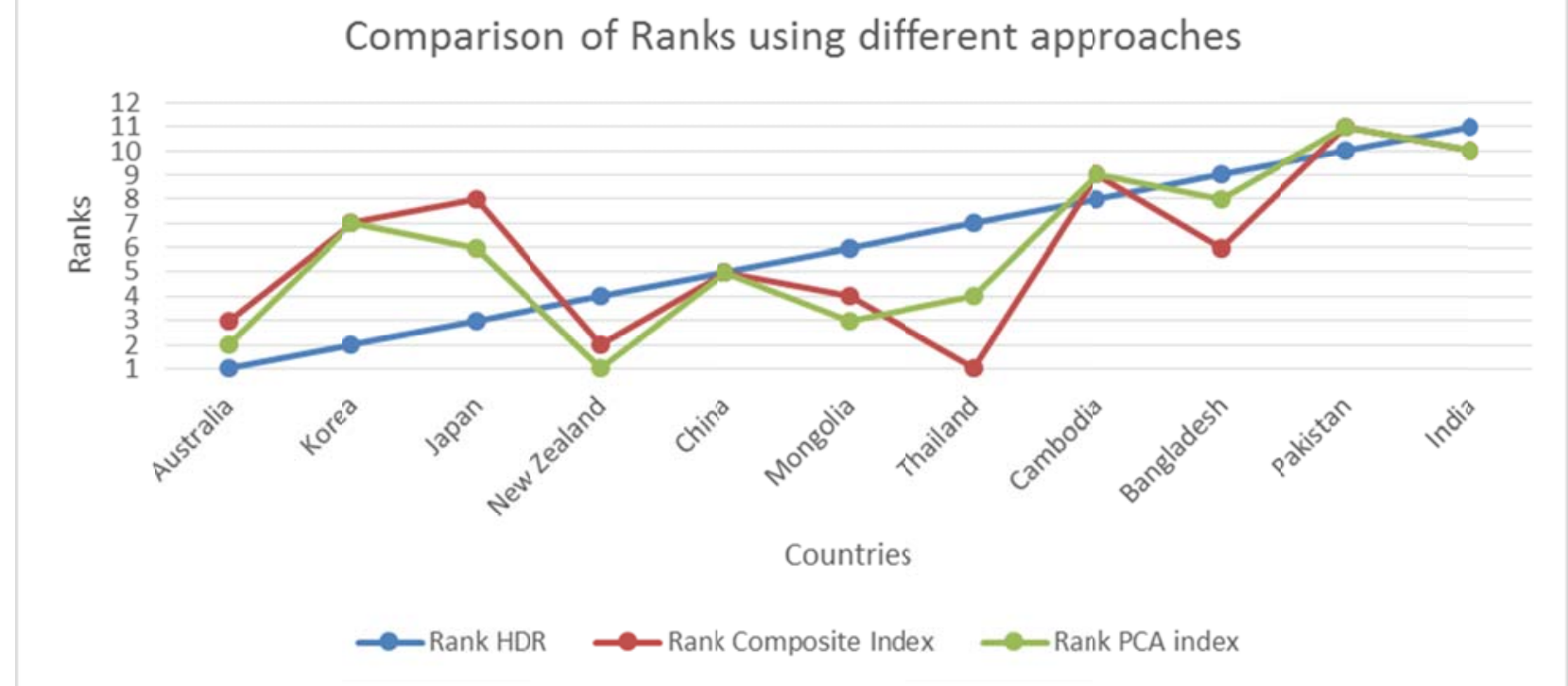

Source: (Basic data), UNDP 2015

The results of the shift in rankings are illustrated in the figure 1. The results reveal that except for countries like China and Cambodia, there is a significant shift in the rankings of various countries from the original GII after incorporating new variables and functional form for the GII construction. Australia starts at rank 1, but falls to rank 2 and 3, respectively, when we use the rational form for GII construction and PCA methodology. For Korea and Japan, too, the rank falls drastically. This indicates that time use is a significant determinant of gender disparity or, in other words, we can say that gender disparity exists in terms of the contribution of men and women to SNA and ext-SNA activities. For New Zealand, the rank improves after the construction of the new GII, implying better economic status for women in the nation. The rank of New Zealand falls to 5 if we construct the GII without using time use survey data (table 14), implying that the 
differentials in time use in New Zealand are relatively smaller compared with other countries. This can be attributed to the fact that New Zealand is one of the most-developed countries in the AsiaPacific region, with many policies drafted to lift the status of women in society. For countries like Mongolia, Thailand, Bangladesh, and India, the rank improves, whereas it falls further for Cambodia and Pakistan (figure 1). At rank 1, Thailand fares best in gender equality using the new functional form. One more thing to note here is that the rankings of various countries using the new functional form and PCA methodology are almost the same, hence justifying the weights assigned to every variable. Apart from that, India and Pakistan are the countries with a significant gender gap and there is a need for a policy revolution in this regard.

If we compare the rankings of countries using the UNDP approach and PCA without incorporating time use data (table 14), the results reveal the ranks of many developed countries fall and improves for countries like Nepal and Bhutan, which can be a result of the implementation of many womencentric policies in the recent past. For Singapore the rank falls from 1 to 9, which implies women are not equal in all the spheres of life in Singapore and there is still significant scope for policy amendments required to address these issues. Using any methodology, we see that Pakistan and India are the countries that fare the poorest among the Asian-Pacific countries in terms of gender equality and the major gap lies in the economic activity and empowerment dimension. Women's access to jobs, education, and technology is still miniscule in these countries and, as a result, their representation at various levels suffers. Patriarchal society and deep-rooted beliefs make it difficult for women to voice their concerns. It is time that government should create policies so that equal access to all opportunities is available irrespective of sex, caste, or religion.

\section{CONCLUSION}

The paper analyzes the developments in the UNDP's gender-related indices and suggests a few alternatives for incorporating an improved choice of variables, functional forms, and weights. While the GII conceptually reflects the loss in achievement due to inequality between men and women in three dimensions - health, empowerment, and labor force participation - we argue that the assumptions and the choice of variables used to capture these dimensions remain inadequate, resulting in the partial capture of gender inequalities. Since the dimensions used for the GII are 
different from the HDI, we cannot say that a higher value of the GII represents loss in the HDI due to gender inequalities.

Another drawback of using the GII is that along with the inequality indicators of women vis-à-vis men, it also takes absolute indicators that are defined specifically only for women. The corresponding values for men for these absolute variables are taken as 1, which is unrealistic and leads to overestimation of the gap between health standards for women and men. Yet another technical obscurity is how to interpret the index constructed by combining women-specific indicators along with the other indicators that are available for both the genders. The GII is a partial construct, as it has not captured significant dimensions of gender inequalities.

Given these caveats of the existing GII, we try to reconstruct the GII in the context of Asia-Pacific using various scenarios. The results revealed that the UNDP GII overestimates the gap between the two genders and found that using women-specific indicators leads to an erroneous estimation of gender inequality. Another major finding is that incorporating the unpaid care economy using the time use statistics in the GII leads to a significant shift in the rankings of various countries. The estimates are illustrative. The implication of the results broadly suggests a return to the GDI for capturing gender development, with an improvised set of choices and variables. 


\section{APPENDIX}

Table 14. Ranking of Countries Using PCA without Incorporating Time Use

\begin{tabular}{lll}
\hline Country & Rank HDR & Rank PCA without time use \\
\hline Australia & 2 & 2 \\
India & 21 & 22 \\
China & 6 & 12 \\
New Zealand & 5 & 1 \\
Japan & 4 & 14 \\
Pakistan & 20 & 23 \\
Korea & 3 & 15 \\
Bangladesh & 19 & 17 \\
Cambodia & 16 & 16 \\
Thailand & 12 & 11 \\
Mongolia & 10 & 6 \\
Indonesia & 18 & 19 \\
Lao People's Dem. Rep & - & 7 \\
Malaysia & 7 & 20 \\
Myanmar & 13 & 3 \\
Nepal & 17 & 13 \\
Papua New Guinea & 22 & 18 \\
Philippines & 14 & 8 \\
Singapore & 1 & 9 \\
Vietnam & 9 & 5 \\
Bhutan & 15 & 10 \\
Kzakhstan & 8 & 4 \\
Sri Lanka & 11 & 21 \\
\hline Saurce: Bac & &
\end{tabular}

Source: (Basic data), UNDP 2015

Table 15. Ranks of Countries Incorporating Time Use

\begin{tabular}{llll}
\hline Country & Rank HDR & Rank Composite Index & Rank PCA index \\
\hline Australia & 1 & 3 & 2 \\
India & 11 & 10 & 10 \\
China & 5 & 5 & 5 \\
New Zealand & 4 & 2 & 1 \\
Japan & 3 & 8 & 6 \\
Pakistan & 10 & 11 & 11 \\
Korea & 2 & 7 & 7 \\
Bangladesh & 9 & 6 & 8 \\
Cambodia & 8 & 9 & 9 \\
Thailand & 7 & 1 & 4 \\
Mongolia & 6 & 4 & 3 \\
\hline
\end{tabular}

Source: (Basic data), UNDP 2015 


\section{REFERENCES}

Adelman, I., and C.T. Morris. 1967. Society, Politics and Economic Development. Baltimore: John Hopkins University Press.

Anand, S., and A. Sen. 1995. "Gender Inequality in Human Development: Theories and Measurement.” Occasional Paper 19. New York: UNDP.

Anand, S., and M. Ravallion. 1993. "Human Development in Poor Countries: On the Role of Private Incomes and Public Services.” Journal of Economic Perspectives 7(Winter).

Bardhan, K., and S. Klasen. 1999. “UNDP's Gender-Related Indices: A Critical Review.” World Development 27(6): 985-1010.

Bartuskova, L., and K. Kubelkova. 2014. "Main Challenges in Measuring Gender Inequality." Proceedings of FIKUSZ ’14: 19-28.

Becker, G. 1965. “A Theory of the Allocation of Time.” The Economic Journal 75(299): 493-517.

Beneria, L., and S. Feldman. 1992. Unequal Burden: Economic Crises, Persistent Poverty, and Women's Work. Boulder, CO: Westview Press.

Beneria, L., and I. Permanyer. 2010. "The Measurement of Socio-economic Gender Inequality Revisited.” Development and Change 41(3): 375-99.

Chakraborty, L. 2014. "Integrating Time in Public Policy: Empirical Description of Genderspecific Outcomes and Budgeting.” Levy Economics Institute Working Paper 785.

Dijkstra, A.G. 2002. "Revisiting UNDP's GDI and GEM: Toward an alternative.” Social Indicators Research 57: 301-38.

Dijkstra, A.G. 2006. "Towards a fresh start in measuring gender equality: A contribution to the debate." Journal of Human Development 7: 275-83.

Ferrant, G. 2009. “A New Way to Measure Gender Inequalities in Developing Countries: The Gender Inequalities Index (GII)." CEAFE Papiers. Available at: http://www.tn.auf.org/CEAFE/Papiers_CEAFE10/MacroI/Ferrant.pdf

Haq, M.U. 1995. Reflections on Human Development. New York: Oxford University Press.

Hawken, A., and G.L. Munck. 2013. "Cross-National Indices with Gender-Differentiated Data: What Do They Measure? How Valid Are They?" Social Indicators Research 111(3): 80138.

Hicks, N. and P. Streeten. 1979. "Indicators of development: The search for a basic needs yardstick." World Development 7: 567-80. 
Klasen, S., and D. Schüler. 2011. "Reforming the Gender-Related Development Index and the Gender Empowerment Measure: Implementing Some Specific Proposals.” Feminist Economics 17(1).

Lahiri, A., L. Chakraborty, and P.N. Bhattacharyya . 2003. "Gender Budgeting in India." UN Women Publication. Available at: http://nipfp.org.in/media/medialibrary/2014/11/GENDER_BUDGETING_IN_INDIA_1.pd $\mathrm{f}$

McGillivray, M. 1991. "The Human Development Index: Yet another redundant composite development indicator?" World Development 19: 1461-68.

McGillivray, M., and H. White. 1993. "Measuring development? The UNDP's Human Development Index.” Journal of International Development 5: 183-92.

Morris, M.D. 1979. Measuring the Condition of the World's Poor: The Physical Quality of Life Index. New York: Pergamon.

Noorbakhsh, F. 1998. “A modified human development index.” World Development 26(3): 51728.

Permanyer, I. 2010. "The Measurement of Multidimensional Gender Inequality: Continuing the Debate." Social Indicators Research 95(2): 181-98.

Permanyer, I. 2013. “A Critical Assessment of the UNDP's Gender Inequality Index." Feminist Economics 19(2): 1-32.

United Nations. 1954. Report on International Definition and Measurement of Standards and Levels of Living. New York: United Nations.

United Nations Development Programme (UNDP). 1995. Human Development Report. New York: UNDP.

UNDP. 2013. "Technical notes calculating the human development indices-graphical presentation” in Human Development Report 2014. New York: UNDP.

UNDP. various years. Human Development Report. New York: UNDP.

UN Inter-agency Group for Child Mortality Estimation (IGME). 2014. "Child Mortality Estimates - Sex-specific Under-five Mortality Rate.” Unicef Global Databases. Available at: data.unicef.org

United Nations Research Institute for Social Development (UNRISD). 1972. Contents and Measurement of Socio-economic Development. New York: Praeger Publishers.

UNSD. 1993. Systems of National Accounts, 1993. New York: United Nations Statistical Division. 